Pavlović, Nataša (2021). 'It felt like we were all hanging out while talking about translation theory': Lessons learned from a flipped translation theory course in emergency remote teaching during the COVID-19 pandemic. Current Trends in Translation Teaching and Learning E, 8, 31 - 85. https://doi.org/10.51287/cttle20213

\title{
'IT FELT LIKE WE WERE ALL HANGING OUT WHILE TALKING ABOUT TRANSLATION THEORY': LESSONS LEARNED FROM A FLIPPED TRANSLATION THEORY COURSE IN EMERGENCY REMOTE TEACHING DURING THE COVID-19 PANDEMIC
}

Nataša Pavlović

University of Zagreb

\begin{abstract}
The role of translation theory in translator education seems to be undergoing a crisis as universities struggle to provide graduates with practical, market-driven skills that will increase their employability. The overnight transition to online delivery in the time of educational disruption caused by the COVID-19 pandemic has only heightened the challenges in making theoretical courses relevant for students. This paper explores the application of the flipped classroom model in a translation theory course on the graduate (MA) level, delivered in the context of emergency remote teaching. The course is described
\end{abstract}


Pavlović, Nataša (2021). 'It felt like we were all hanging out while talking about translation theory': Lessons learned from a flipped translation theory course in emergency remote teaching during the COVID-19 pandemic. Current Trends in Translation Teaching and Learning E, 8, 31 - 85. https://doi.org/10.51287/cttle20213

and evaluated with the help of student feedback $(\mathrm{N}=30)$ elicited via an online questionnaire. The main source of data are responses to open-ended questions, which are analysed qualitatively. The data are coded for general perceptions of the flipped classroom and its four course components (videos, experimental translation assignments, forum discussion assignments, synchronous Zoom discussions), as well as for perceptions of teacher support. Lessons are drawn for emergency remote teaching but also for future face-to-face teaching of theory-oriented translation courses.

Keywords: flipped classroom, teacher support, translation theory, emergency remote teaching, YouTube, Zoom

\section{INTRODUCTION AND CONTEXT}

To say that the teaching of translation theory is experiencing a crisis is probably not a gross exaggeration. Amidst institutions' and teachers' growing concerns to ensure employability for their students, and the students' own desire to devote their scarce time to practical, applicable activities that will help them gain an edge when entering the profession, translation theory can appear almost irrelevant. It is like a relic of past times when humanities could afford to dedicate hours and hours to the pursuit of knowledge for knowledge's sake. The decline in the perceived relevance of translation 
Pavlović, Nataša (2021). 'It felt like we were all hanging out while talking about translation theory': Lessons learned from a flipped translation theory course in emergency remote teaching during the COVID-19 pandemic. Current Trends in Translation Teaching and Learning E, 8, 31 - 85. https://doi.org/10.51287/cttle20213

theory is thus perhaps reflective of a broader trend of declining interest in humanities (cf. Nietzel, 2019). It might also be due to the way translation theory is sometimes taught, without a clear link to practice, and without important professional trends (e.g., the impact of technology) being incorporated into theoretical frameworks ${ }^{1}$.

Little empirical evidence has been found to confirm that translation theory helps students acquire translation competence (Di Mango, 2019). Furthermore, students might not apply theoretical concepts in their practical translation tasks to a great extent (Vottonen \& Kujamäki, 2021). On the other hand, there are also indications that students consider learning about translation theory to be essential (Agost \& Pilar Ordóñez López, 2015). Therefore, the jury is still out with respect to the place of theory in translator education, and empirical research, in particular, is required to inform the discussion.

In this paper, I take the view that translation theory has, and will continue to have, an important role in translator education and that the key issue is how to

\footnotetext{
${ }^{1} \mathrm{I}$ am grateful to one of the reviewers for pointing out the latter important issue.
} 
Pavlović, Nataša (2021). 'It felt like we were all hanging out while talking about translation theory': Lessons learned from a flipped translation theory course in emergency remote teaching during the COVID-19 pandemic. Current Trends in Translation Teaching and Learning E, 8, 31 - 85. https://doi.org/10.51287/cttle20213

make it relevant and interesting for today's translation students. Since this action-research study will involve reflection on my own teaching practice, I should explain that this position arises in part from my involvement in translation teaching, which spans more than two decades. In the translation theory course, which I have taught for 12 years, I have attempted to make the theory relevant by making explicit its link to practice. I have done so by including assignments, such as experimental translations, that were not done for their own sake but rather as starting points for discussion about theoretical issues (cf. Agost \& Ordóñez-López, 2018, p. 79). My aim has been to provide students with the conceptual apparatus and metalanguage of contemporary theories that would inform their future practice as professional translators (cf. Shuttleworth, 2001). Previous student feedback on the course had generally been very good, if not overly enthusiastic. Over the years I had developed some tricks to make the course engaging and interactive, which had worked reasonably well in the classroom setting. However, in the winter semester of 2020/2021, the COVID-19 pandemic forced me, like so many colleagues all over the world, to deliver this course remotely for the first time. The challenge was to adapt it to the online 
Pavlović, Nataša (2021). 'It felt like we were all hanging out while talking about translation theory': Lessons learned from a flipped translation theory course in emergency remote teaching during the COVID-19 pandemic. Current Trends in Translation Teaching and Learning E, 8, 31 - 85. https://doi.org/10.51287/cttle20213

format in circumstances that are best described as "emergency remote teaching" (ERT; Bozkurt \& Sharma, 2020), that is, without much time for planning and preparation, and without the course participants having deliberately chosen this format.

The results of a previous small-scale study I conducted with a colleague (Stanojević \& Pavlović, in press) in July 2020 seemed to suggest that practical translation courses were more easily adapted to emergency remote teaching than theoretical ones. Based on their experience with ERT in the spring of 2020, the participants in that qualitative study, nine translation teachers from three universities, were of the opinion that practical classes had consisted of translation assignments and feedback (quite like translators' professional work) even before the pandemic, which could just as easily be replicated in ERT. However, in their view, helping students acquire theoretical knowledge and metacognitive skills required more effort and creativity. Some of them indicated that in their theoretical courses they had resorted to what was in effect the flipped classroom model (see 2.1.).

I took their opinions and experiences on board when planning my own translation theory course in the 
Pavlović, Nataša (2021). 'It felt like we were all hanging out while talking about translation theory': Lessons learned from a flipped translation theory course in emergency remote teaching during the COVID-19 pandemic. Current Trends in Translation Teaching and Learning E, 8, 31 - 85. https://doi.org/10.51287/cttle20213

autumn of 2020. Given the ongoing pandemic, it seemed more pressing than ever - and more challenging at the same time - for the course to be relevant, not to feel like a waste of time. Factors such as the online format itself (which the students had not voluntarily chosen and which they felt was cognitively more demanding than face-to-face classes), the fact that many teachers were overcompensating for the lack of personal contact by giving students too many tasks, as well as the psychological pressures of life amidst the pandemic threatened to make students overwhelmed early on in the semester. For this reason, I wanted to cater to students' academic but also psychosocial needs. I wanted the course to be interesting and engaging; to be a platform where they could freely discuss translation-related issues and experiment with translations, but also have the opportunity to interact with each other since their peer-to-peer social contacts were severely limited. I also wanted to use the combination of synchronous and asynchronous modes because I wanted to make most of both worlds: the flexibility of the asynchronous approach and the live contact afforded by the synchronous classes. 
Pavlović, Nataša (2021). 'It felt like we were all hanging out while talking about translation theory': Lessons learned from a flipped translation theory course in emergency remote teaching during the COVID-19 pandemic. Current Trends in Translation Teaching and Learning E, 8, 31 - 85. https://doi.org/10.51287/cttle20213

For all of these reasons, I decided to use the flipped classroom model for my translation theory course. In this article, I aim to describe that course and present the results of its evaluation by the participants, drawing at the same time some lessons that can be learned from ERT and applied to future translation theory teaching at the end of the current educational disruption. I will start by providing a short theoretical background on the key concepts of 'flipped classroom' and 'teacher support', which are particularly relevant for ERT. I will then describe the course as I delivered it in ERT conditions. Next, I will explain the details of how the evaluation was conducted (participants and method) before presenting the results of the evaluation. Finally, I will discuss some implications for future teaching of translation theory, both online and face to face.

\section{THEORETICAL BACKGROUND}

\subsection{Flipped classroom}

The flipped classroom model is not an overly novel idea, although studies investigating its application in translator education are still rare and do not specifically focus on translation theory teaching (Gerber et al., 2020; Shu, 2015; Tsai \& Tsai, 2017). 
Pavlović, Nataša (2021). 'It felt like we were all hanging out while talking about translation theory': Lessons learned from a flipped translation theory course in emergency remote teaching during the COVID-19 pandemic. Current Trends in Translation Teaching and Learning E, 8, 31 - 85. https://doi.org/10.51287/cttle20213

A flipped classroom is essentially a model of instruction in which activities that are traditionally done in class are done outside the classroom and vice versa (Bergmann \& Sams, 2012, p. 13). This primarily means that direct instruction (i.e., lectures) is displaced from the classroom, and content is made available to students in other formats, such as videos, assigned reading, problemsolving assignments etc., to be studied before class (Centre for Teaching, Learning and Technology, n.d.). The in-class time is then used for discussion, reflection, application and other activities "stimulating the upper levels of Bloom's taxonomy of cognitive skills" (ibid.). In online delivery, including ERT, the "out-of-class" activities are done asynchronously, in students' own time within a given period, while "in-class" activities take place in the synchronous mode, typically via video conferencing platforms such as Zoom, Microsoft Teams or BigBlueButton, to mention but a few.

\subsection{Teacher support}

Teacher support has been defined along three dimensions - structure, autonomy and involvement - that foster students' basic psychological needs. These needs are, according to self-determination 
Pavlović, Nataša (2021). 'It felt like we were all hanging out while talking about translation theory': Lessons learned from a flipped translation theory course in emergency remote teaching during the COVID-19 pandemic. Current Trends in Translation Teaching and Learning E, 8, 31 - 85. https://doi.org/10.51287/cttle20213

theory (Deci \& Ryan, 2000), the need for competence, autonomy and relatedness. When these needs are met, students (and people in general) experience "effectiveness and mastery", "a sense of integrity" and "feeling significant to others" respectively (Vansteenkiste, n.d.). When the needs are frustrated, people experience "failure and helplessness", being "pushed in an unwanted direction" and "a sense of social alienation, exclusion and loneliness" (ibid.).

The need for competence is upheld through teacher support when students are provided with the optimum amount of structure helping them to effectively achieve learning outcomes. Structure support therefore involves clear communication of expectations, consistency, instrumental help and adjustment of teaching strategies (Skinner \& Belmont, 1993, p. 572). A lack of support in this respect is perceived as chaos. The need for autonomy is enhanced through autonomy support. This refers to the freedom of choice students are offered in determining their behaviour, and specifically involves the provision of choices or options in the learning process; respect for and acknowledgement of students' opinions, feelings and agendas; and provision of relevance (rationale) 
Pavlović, Nataša (2021). 'It felt like we were all hanging out while talking about translation theory': Lessons learned from a flipped translation theory course in emergency remote teaching during the COVID-19 pandemic. Current Trends in Translation Teaching and Learning E, 8, 31 - 85. https://doi.org/10.51287/cttle20213

for class activities (Skinner \& Belmont, 1993, pp. 573-4). A lack of autonomy support is perceived as coercion or pressure (external or internal). Finally, students' need for relatedness is supported through involvement. Teachers are perceived as being involved when they are seen as caring for their students, are attuned to their needs (e.g., show understanding), are available when needed, and dedicate resources (aid, time and energy) to them (ibid.). A lack of this type of support is perceived as rejection or neglect.

Students' perceptions of teacher support have been found to contribute to changes in student engagement and participation in classroom (Skinner et al., 2008). More recently, a systematic review of 65 studies encompassing nearly 60 thousand participants found a significant link between teacher support and students' academic emotions, with the positive correlation between teacher support and positive academic emotions being strongest precisely among students in higher education (Lei, Cui \& Chiu, 2018, p. 9). In the context of the pandemic, when the university students' ties with peers are severely limited, compensatory teacher support could be an important pathway through which students' positive academic emotions can be 
Pavlović, Nataša (2021). 'It felt like we were all hanging out while talking about translation theory': Lessons learned from a flipped translation theory course in emergency remote teaching during the COVID-19 pandemic. Current Trends in Translation Teaching and Learning E, 8, 31 - 85. https://doi.org/10.51287/cttle20213

mobilized in the service of improved learning outcomes (cf. Lei, Cui \& Chiu, 2018, p. 8).

The flipped classroom might be considered as a suitable venue for teachers to offer the three dimensions of support to their students, especially student autonomy, but also structure and involvement. In the context of the pandemic, using the synchronous time together to engage in meaningful interaction rather than knowledge transmission can be expected to encourage the kinds of teacher-student (and student-student, for that matter) relationships that are rich in all three dimensions of support. This paper explores whether these expectations proved to be true when the flipped classroom model was used in a translation theory course during the time of COVID-19 pandemic, and to draw some lessons for the time when translator education returns to classrooms.

\section{COURSE DESCRIPTION}

Translation Theory is an obligatory course for students enrolled in the first year of the graduate (MA) program in English, Translation Stream, at the University of Zagreb, Croatia. Translation stream cohorts are usually around 30 students, and the 
Pavlović, Nataša (2021). 'It felt like we were all hanging out while talking about translation theory': Lessons learned from a flipped translation theory course in emergency remote teaching during the COVID-19 pandemic. Current Trends in Translation Teaching and Learning E, 8, 31 - 85. https://doi.org/10.51287/cttle20213

course is also open to a smaller number of nontranslation students who can take it as an elective. It is a one-semester course with a total of 60 contact hours $^{2}$, normally given in a classroom in two 90minute sessions (on two separate days).

In the winter semester of 2020/2021, the course had to be adapted to non-classroom conditions due to the COVID-19 pandemic. Following the flipped classroom model defined in 2.1., I structured the course as follows: instead of the 90-minute slot I normally had on Tuesdays, students were asked to watch a short video accompanied by an assignment (see 3.2. for details), for which they had about a week at their disposal. They had to do it before Thursday, when we had a synchronous class via Zoom.

\subsection{Videos $^{3}$}

To create the flipped classroom, I decided to make short videos on the topics covered in the course (e.g., translation equivalence, skopos theory, norms in translation, cultural turn in translation studies,

\footnotetext{
2 Contact hour $=45$ minutes.

${ }^{3}$ See Appendix 1 for links to sample videos.
} 
Pavlović, Nataša (2021). 'It felt like we were all hanging out while talking about translation theory': Lessons learned from a flipped translation theory course in emergency remote teaching during the COVID-19 pandemic. Current Trends in Translation Teaching and Learning E, 8, 31 - 85. https://doi.org/10.51287/cttle20213

translation ethics etc.). The video materials students had to view each week lasted 25-35 minutes (one longer or two shorter videos were provided to the maximum length of 35 minutes combined). I recorded the videos on my laptop, in my living room, with no dedicated equipment. Since I wanted to record the screen with PowerPoint slides, as well as myself (PIP feature), I used Screencastify Record, the unlimited version ${ }^{4}$. It is very user friendly and can be set up to store the recordings directly on Google Drive. It was mostly reliable, although some gaps in sound recording occurred from time to time. I used Wondershare Filmora ${ }^{5}$ to edit the videos which, for the basic editing functions, does not require a long learning curve or highly specialist knowledge. Since I had to record half an hour of video each week in addition to my other obligations, I needed simple solutions that would enable me to keep up the pace for 15 weeks.

YouTube was chosen as the platform to share the videos since it is a) free; b) easy to use; c) the students are already familiar with it; d) streaming is not demanding in terms of data usage (an important

\footnotetext{
${ }^{4}$ The free version enables recording up to 5 minutes, which can be enough in combination with video editing software.

5 There are excellent free alternatives also available, such as OpenShot.
} 
Pavlović, Nataša (2021). 'It felt like we were all hanging out while talking about translation theory': Lessons learned from a flipped translation theory course in emergency remote teaching during the COVID-19 pandemic. Current Trends in Translation Teaching and Learning E, 8, 31 - 85. https://doi.org/10.51287/cttle20213

consideration since not all students had flat-rate WiFi plans). I created a YouTube channel, Translation Matters ${ }^{6}$, but the videos were shared as unlisted (i.e., they could be viewed by those who had a link). The links were made available to students in the e-course on the university's Moodlebased e-learning platform, which was the central place for the sharing of materials, assignments and communication.

I created a logo, as well as an introductory and a closing clip for all the videos in order to have a recognizable identity and achieve cohesion among the videos. The most challenging aspect of video making was striking the right balance between scholarly and accessible. I used a light tone and some comical effects to make the videos more engaging, while at the same time trying not to oversimplify or trivialize the issues discussed.

\subsection{Assignments}

All videos were accompanied by assignments, first of all, because this was a simple way to make sure

\footnotetext{
${ }^{6}$ I was not aware at the time of a translation studies journal of the same name that had been launched in the previous year. The same name is purely coincidental.
} 
Pavlović, Nataša (2021). 'It felt like we were all hanging out while talking about translation theory': Lessons learned from a flipped translation theory course in emergency remote teaching during the COVID-19 pandemic. Current Trends in Translation Teaching and Learning E, 8, 31 - 85. https://doi.org/10.51287/cttle20213

the students would watch the videos. The flipped classroom model rests on the idea that students will do the work assigned before the class; otherwise, they will not be able to participate fully in the ensuing discussions and therefore benefit from the model. An equally important purpose of the assignments was for the students to apply or test the knowledge gained from the videos, and also to show them the relevance of the theoretical content covered.

I used two basic types of assignments. One type involved a group or individual experimental translation. For instance, when the topic of the video was skopos theory, students had to translate a number of newspaper ads in groups. The point was to challenge the notion of equivalence learned about in previous classes. Or, for the video dealing with different translation strategies, students were given a short excerpt from a book containing many cultural references and asked to produce several translations, each using a different overall strategy.

The second type of assignment was a forum assignment. Using the online forum in the Moodle e-course, students had to contribute to a discussion on a given topic by, for example, illustrating 
Pavlović, Nataša (2021). 'It felt like we were all hanging out while talking about translation theory': Lessons learned from a flipped translation theory course in emergency remote teaching during the COVID-19 pandemic. Current Trends in Translation Teaching and Learning E, 8, 31 - 85. https://doi.org/10.51287/cttle20213

translation norms they thought were in force in their culture, finding instances of censorship in translation or giving their opinion on feminist translation interventions. The contributions were expected to be short and served to make students think and prepare ground for the synchronous discussions via Zoom.

\subsection{Synchronous Zoom discussions}

The final part of the weekly activities involved a 90minute synchronous Zoom session during which the topic of the week was discussed. No content was delivered in lecture format over the Zoom; this "face time" (Sams \& Bergmann, 2013) was reserved only for the clarification of issues, discussion and an opportunity for students to ask questions (of each other and the teacher). As Begrmann and Sams (2012, p. 47) point out, "despite the attention that the videos get, the greatest benefit to any flipped classroom is not the videos. It's the in-class time that every teacher must evaluate and redesign".

Zoom was the platform of choice based on experience, both mine and of the participants in a previous study (Stanojević \& Pavlović, in press). The Pro version without a time limit was used, with 
Pavlović, Nataša (2021). 'It felt like we were all hanging out while talking about translation theory': Lessons learned from a flipped translation theory course in emergency remote teaching during the COVID-19 pandemic. Current Trends in Translation Teaching and Learning E, 8, 31 - 85. https://doi.org/10.51287/cttle20213

additional storage for the recordings. It allowed all the 39 participants (38 students and the teacher) to use their cameras at the same time, proving to be very stable, with no serious incidents experienced throughout the semester. Recording to the cloud and the sharing of recorded sessions were very easy. I wanted to make the recordings of live classes available for those students who might have to miss a class for health or other reasons, as well as those who might want to listen again to a part of the session they did not catch (e.g., if they lost their internet connection for a while or were disturbed in another way). The recordings only remained available for two weeks, as I wanted to encourage students to watch the missed class as soon as possible to be able to follow the rest of the course unhindered. In the end, absences turned out to be quite rare.

\section{COURSE EVALUATION}

\subsection{Participants and method}

The 2020/2021 edition of the Translation Theory course was evaluated a few days after the last class was held, in the second half of January 2021. Thirtyeight students had taken the course -28 translation 
Pavlović, Nataša (2021). 'It felt like we were all hanging out while talking about translation theory': Lessons learned from a flipped translation theory course in emergency remote teaching during the COVID-19 pandemic. Current Trends in Translation Teaching and Learning E, 8, 31 - 85. https://doi.org/10.51287/cttle20213

stream students, for whom this course was obligatory, and 10 others, for whom it was an elective course and two of whom were Erasmus exchange students. Of the 38, 30 filled out an online questionnaire created to elicit their perceptions of the course. The questionnaire (see Appendix 2) was rather simple, as the aim was for as many participants to respond. It consisted of 12 questions, seven of which were open-ended. Of the closed questions, three used Likert-type scales and two single-select multiple choice. The participants were strongly encouraged to respond to open-ended questions as well, which most did. No demographic data were collected on the participants, as this might have jeopardized anonymity and in the context of a university course utmost anonymity was deemed a crucial prerequisite for getting honest opinions from the participants.

The responses to the closed questions were analysed quantitatively, using descriptive statistics only. Only one question used a proper Likert scale (Q5), for which the mean value was calculated. Since the other two Likert-type scales (Q1 and Q7) were treated as ordinal rather than interval, only the absolute frequencies were provided when reporting 
Pavlović, Nataša (2021). 'It felt like we were all hanging out while talking about translation theory': Lessons learned from a flipped translation theory course in emergency remote teaching during the COVID-19 pandemic. Current Trends in Translation Teaching and Learning E, 8, 31 - 85. https://doi.org/10.51287/cttle20213

on those questions (cf. Mellinger \& Hanson, 2017, p. 26).

Open-ended responses formed the main source of data. I analysed them qualitatively, coding for general perceptions of the flipped classroom and its four course components (videos, experimental translation assignments, forum discussion assignments, synchronous Zoom discussions), as well as for perceptions of teacher support. NVivo software was used to facilitate the qualitative part of the analysis.

\subsection{Results}

4.2.1. General perceptions of the flipped translation theory course

The course was evaluated very positively. The fact that 30 of the 38 students responded to the questionnaire and that all of the respondents replied to at least three open-ended questions (27 replied to four; 24 replied to five) is in itself an indicator of the high level of engagement with the course. Students liked the "conversational way" in which the course was delivered and appreciated the link between 
Pavlović, Nataša (2021). 'It felt like we were all hanging out while talking about translation theory': Lessons learned from a flipped translation theory course in emergency remote teaching during the COVID-19 pandemic. Current Trends in Translation Teaching and Learning E, 8, 31 - 85. https://doi.org/10.51287/cttle20213

theory and practice. These are some illustrative opinions expressed by the participants:

This course connected theory and practice, it wasn't necessary to learn by heart a bunch of abstract definitions, but instead the topics were delivered in an interesting way, making us critically think and form our own opinions and attitudes toward some relevant issues. (P5)

Sometimes theory tends to be boring, but in this course it seemed like we were just talking and discussing, yet we learned a lot. (P6)

Even though we are talking about theory, we did it in a really practical, interesting and fun way, which makes the knowledge stick. (P9)

This was the only class in which I didn't feel as if I was losing something because it was delivered online. In fact, videos made it even better because I could go back and watch them again. (P13)

Since I could not compare this edition of the course with its previous editions, I asked the participants to compare the course under evaluation to other theoretical courses they had had during their studies (Q3). This was a single-select multiple choice question, with a focus on delivery. The question was 
Pavlović, Nataša (2021). 'It felt like we were all hanging out while talking about translation theory': Lessons learned from a flipped translation theory course in emergency remote teaching during the COVID-19 pandemic. Current Trends in Translation Teaching and Learning E, 8, 31 - 85. https://doi.org/10.51287/cttle20213

phrased in the following way: "In terms of the WAY it was delivered (i.e., not the topic itself), how does this course compare to other THEORETICAL courses you've had during your years at the university?" The options offered are shown below, together with the number of participants who chose each option:

- The delivery of most other theoretical courses was much better than this one. (0)

- The delivery of most other theoretical courses was better than this one. (0)

- The delivery of this course was neither better nor worse than most other theoretical courses. (2)

- This delivery of this course was better than the delivery of most other theoretical courses. (14)

- This delivery of this course was much better than the delivery of most other theoretical courses. (14)

As can be seen, the course was compared favourably or very favourably to other theoretical courses by 28 of the 30 respondents. The two remaining respondents put it on a par with other theoretical courses they had had. Participants were given an opportunity to "explain or comment" on their response (Q4). Twenty-one people took the time to elaborate, and these are two typical responses: 
Pavlović, Nataša (2021). 'It felt like we were all hanging out while talking about translation theory': Lessons learned from a flipped translation theory course in emergency remote teaching during the COVID-19 pandemic. Current Trends in Translation Teaching and Learning E, 8, 31 - 85. https://doi.org/10.51287/cttle20213

Other theoretical courses usually consist of memorising what other people said in a certain period of time on a certain topic, while this course focused on critical thinking. (P15)

The goal of the course was not to memorize the definitions, classifications or authors, but to think critically about everything. [...] I think that because of such a model of classes I will retain everything we did for much longer in my memory than if I'd only had to cram. (P26)

Another attempt to solicit the participants' general perception of this course was question 5 , in which they were asked to rate their agreement on a Likert scale ( 1 = "strongly disagree"; 5 = "strongly agree") with the following statement: "Even if this course was not obligatory for translation students, I would still recommend it to colleagues who wish to become translators." The participants strongly agreed (26) or agreed (4) with the statement, the mean response value being 4.87 .

Question 7 asked the participants to assess how much they had learned about translation in this course. The Likert-type scale was from $1=$ "almost nothing new or useful" to $5=$ "a lot of new and useful stuff". Twenty-two participants chose the 
Pavlović, Nataša (2021). 'It felt like we were all hanging out while talking about translation theory': Lessons learned from a flipped translation theory course in emergency remote teaching during the COVID-19 pandemic. Current Trends in Translation Teaching and Learning E, 8, 31 - 85. https://doi.org/10.51287/cttle20213

highest grade, seven opted for grade 4 and one participant chose the mid-point.

\subsubsection{Perception of the course components}

In question 1, the respondents were asked to rate the usefulness of each course component on a Likerttype scale (Fig. 1).

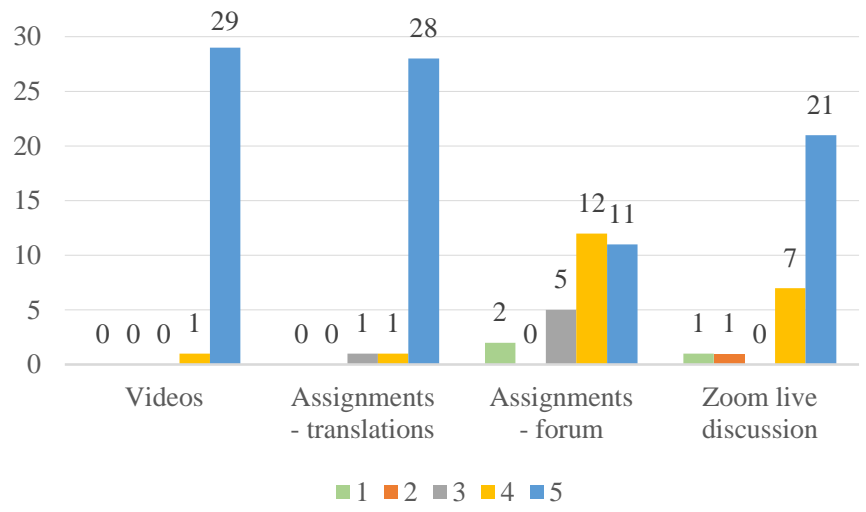

Figure 1 - Participants' $(\mathrm{N}=30)$ evaluation of course elements $(1=$ "not at all useful"; 5 = "very useful")

As Figure 1 shows, the videos were the most highly rated: 29 of the 30 participants gave them the highest grade (5, "very useful"), and one participant the second highest grade. The videos were followed by 
Pavlović, Nataša (2021). 'It felt like we were all hanging out while talking about translation theory': Lessons learned from a flipped translation theory course in emergency remote teaching during the COVID-19 pandemic. Current Trends in Translation Teaching and Learning E, 8, 31 - 85. https://doi.org/10.51287/cttle20213

the experimental translation assignments, which 28 participants thought were very useful, one considered useful, and one chose the mid-point. Forum assignments and Zoom discussions received more varied results. Forum assignments were considered useful or very useful by 23 participants but two found them not at all useful, with the remaining five choosing the mid-point. Ratings for Zoom live discussions also ranged from 1 to 5, with 28 considering them useful or very useful, and two participants not useful.

In question 2, which was open-ended, the participants were given the opportunity to "explain or comment" on their responses to Q1, which all of the 30 respondents did. I present their views in more detail below.

\subsubsection{Videos}

The videos were very highly praised by all of the participants. They were described as being "creative", "interesting", "informative", "well structured", "clear", "easy to watch", "fun", and "amusing". Student feedback affirmed their appreciation of the videos: 
Pavlović, Nataša (2021). 'It felt like we were all hanging out while talking about translation theory': Lessons learned from a flipped translation theory course in emergency remote teaching during the COVID-19 pandemic. Current Trends in Translation Teaching and Learning E, 8, 31 - 85. https://doi.org/10.51287/cttle20213

[The] videos were extremely useful, I'd say that they were the best mode of delivery I've encountered in online teaching. (P25)

Unfortunately, the scale goes only up to 5. If I could, I'd give the videos a 10. I cannot put into words how surprised and glad I was [about] the videos. [...] I think that recorded lessons in themselves are usually very practical because you can watch/listen to them at your own convenience (or easily go back to something that you didn't understand), but this was a whole new level. (P30)

The videos were amazing. I enjoyed the playfulness at the beginning and the structured way the information was presented. Not to be too dramatic, but they were the highlight of my studies this year. :) (P19)

I think videos are a great replacement for live lectures, as students can rewatch them to catch up on everything presented in the video. The extra effort to make them amusing is also greatly appreciated. (P4)

I should point out that I used a separate rating form to evaluate the technical aspects of the videos in terms of sound and image quality, font size and legibility, amount of text, and video length. Twenty course participants filled out that form. The length of the videos was assessed as neither too long nor 
Pavlović, Nataša (2021). 'It felt like we were all hanging out while talking about translation theory': Lessons learned from a flipped translation theory course in emergency remote teaching during the COVID-19 pandemic. Current Trends in Translation Teaching and Learning E, 8, 31 - 85. https://doi.org/10.51287/cttle20213

too short. Font size and the amount of text were also considered appropriate, as was, for the most part, image quality (4.4/5). Sound was slightly lower rated (3.95) and a number of participants pointed out "minor sound issues from time to time". It was further suggested that the font "could be changed to something more legible".

When the technical evaluation of the videos is related to the high scores they received in the main questionnaire, it becomes clear that the videos do not have to be technically perfect to fulfil their role in the flipped classroom and to be highly appreciated by the students. This finding should be encouraging to all teachers considering the use of videos but worrying that they will not be able to produce professional quality.

\subsubsection{Experimental translation assignments}

The translation assignments were also very well received. In addition to describing them in general terms as "interesting", "useful", "enjoyable" and "fun", the participants also offered more specific comments: 
Pavlović, Nataša (2021). 'It felt like we were all hanging out while talking about translation theory': Lessons learned from a flipped translation theory course in emergency remote teaching during the COVID-19 pandemic. Current Trends in Translation Teaching and Learning E, 8, 31 - 85 . https://doi.org/10.51287/cttle20213

They were all very interesting (especially the song translation and ad translation). Usually, the theoretical courses boil down to just heaps of information that we learn for the exam and then forget, but these tasks really do help retain the information better. (P7)

[T] hey allowed us to use what we learned in the videos in practice and solve tasks with the acquired knowledge. (P10)

The assignments usually nicely complemented the videos and helped me see how the knowledge provided worked in practice. $(\mathrm{P} 19)$

Assignments were also very useful because it was easier to understand the theory after applying it to a particular task. (P25)

Assignments were at times demanding, but they were always well structured to fit the purpose of a certain topic. (P29)

It should be pointed out that some of these were group assignments, which had the added benefit of fostering student-student interaction, an important consideration in the context of the pandemic. As one participant pointed out, "getting to know people in the course while doing tasks with them was very enjoyable" (P21). 
Pavlović, Nataša (2021). 'It felt like we were all hanging out while talking about translation theory': Lessons learned from a flipped translation theory course in emergency remote teaching during the COVID-19 pandemic. Current Trends in Translation Teaching and Learning E, 8, 31 - 85. https://doi.org/10.51287/cttle20213

\subsubsection{Discussion forum assignments}

As could be seen in Figure 1, the discussion forum assignments were more of a mixed bag when it comes to the participants' perceptions. Some participants appreciated them, as can be seen from the following two comments:

I usually don't like these types of assignments, but the ones done in this class were very good [...]. It was also interesting to read about different opinions and experiences my colleagues had. (P30)

I liked the forum discussions; I thought they would be stilted and a waste of time, but I ended up really enjoying reading my colleagues' ideas and responding to them. (P23)

However, most participants thought they were "tedious" and "repetitive". They were "hard to navigate since there are a lot of students". These three participants elaborate:

[M]y experience with the Forum assignments was such that I was always overwhelmed by the number of opinions and responses, that I never managed to give them a proper look. (P14) 
Pavlović, Nataša (2021). 'It felt like we were all hanging out while talking about translation theory': Lessons learned from a flipped translation theory course in emergency remote teaching during the COVID-19 pandemic. Current Trends in Translation Teaching and Learning E, 8, 31 - 85. https://doi.org/10.51287/cttle20213

However, the forum assignments were tedious, due to the fact that they required reading all the previous responses and boiled down to everyone rushing to post something so that they would have to read the least possible number of other people's responses. (P20)

[T]o take part in the assignment I would have to read all of that text, to avoid repeating what someone already said and to see what is being talked about, etc. [...] keeping track of all of that is quite time-consuming and annoying. (P21)

While the participants could see the point of these assignments, they did not enjoy them as much as the rest of the course, as can be seen in these responses:

I personally didn't enjoy the forum assignments because they seemed unproductive. However, I understand they are meant to simulate the discussion we would have in class and make us think of the topic at hand [...]. (P19)

While the idea behind [the forum assignments] that we watch a video and/or do some reading on a given topic and then discuss on the forum is great, the execution was not really good. $(\mathrm{P} 21)$

Forum assignments always made me somewhat nervous as I felt too self-conscious as to what others will say about my responses. It's more about the personal 
Pavlović, Nataša (2021). 'It felt like we were all hanging out while talking about translation theory': Lessons learned from a flipped translation theory course in emergency remote teaching during the COVID-19 pandemic. Current Trends in Translation Teaching and Learning E, 8, 31 - 85. https://doi.org/10.51287/cttle20213

pressure I feel. The topics of this kind of assignments were useful and they helped structure knowledge. (P29)

Several participants pointed out that the drawbacks of the forum assignments were related to the platform used:

[D] ue to the [Moodle] forum being somewhat clumsy, the discussions in the forum came off rigid at times, with people talking past each other and repeating some of the points that had already been made. (P12)

Upgrades to the use of the forum would be beneficial, but that has more to do with [Moodle] as a platform. (P1)

The problem I had with the forum assignments is more due to the system itself and the way it works than the assignments. (P18)

Compared with the social networking sites students are used to, the Moodle-based forum interface comes across as a bit old-fashioned and does not foster interaction as much. For instance, there are no emoticons and no "reaction" buttons, and it is not always possible to keep track of who has responded to whom. 
Pavlović, Nataša (2021). 'It felt like we were all hanging out while talking about translation theory': Lessons learned from a flipped translation theory course in emergency remote teaching during the COVID-19 pandemic. Current Trends in Translation Teaching and Learning E, 8, 31 - 85. https://doi.org/10.51287/cttle20213

\subsubsection{Synchronous discussions via Zoom}

In question 6, participants were asked to rate their engagement in the Zoom discussions, and the options offered were the following (the number of participants who selected a given option is shown in brackets):

- I took an active part in the discussions a lot of the time. (4)

- I listened actively, and sometimes spoke. (12)

- It was mostly passive; I listened but did not speak much. (13)

- I listened, but only with "one ear". (0)

- I connected to the meeting because I felt I should, but I did not really listen to discussions. (0)

The remaining one participant choose the option Other and elaborated: "I listened actively but since I'm usually shy and don't speak up in classes the same happened in this class." (P15)

In the open-ended question on course components (Q2), participants provided more elaborate views of the Zoom discussions. Most found this course component "interesting", "easy to follow", "useful" and "dynamic", with these participants summing up 
Pavlović, Nataša (2021). 'It felt like we were all hanging out while talking about translation theory': Lessons learned from a flipped translation theory course in emergency remote teaching during the COVID-19 pandemic. Current Trends in Translation Teaching and Learning E, 8, 31 - 85. https://doi.org/10.51287/cttle20213

the benefits also expressed by others:

The Zoom classes were easy to follow and interesting, since a discussion always took place. (P10)

Although I did not always have something to contribute to the discussions, I found them very useful because I heard many new perspectives on translation issues that I had not considered before. (P12)

The participants also appreciated the sense of community these synchronous discussions engendered and the atmosphere in the discussions, as these comments testify:

The atmosphere was always nice and friendly and it felt like we were all hanging out while talking about translation theory. (P10)

[T] he conversations during the seminars with all (or at least most) of the people having their cameras on, gave a bit of a feeling as if we were [face to face], so kudos for that. Personally, I was able to focus a bit more because of it. (P27)

My least favorite part is always the participation, mostly because I don't really like speaking in front of people and it is an even more unpleasant experience on Zoom. However, you made Zoom a very welcoming space and 
Pavlović, Nataša (2021). 'It felt like we were all hanging out while talking about translation theory': Lessons learned from a flipped translation theory course in emergency remote teaching during the COVID-19 pandemic. Current Trends in Translation Teaching and Learning E, 8, 31 - 85. https://doi.org/10.51287/cttle20213

gave everyone a chance to speak. I felt heard and like my opinions and thoughts mattered and it was nice to hear colleagues express their own views and opinions. (P19)

The positive atmosphere was probably the biggest plus in my book, because it allowed me to be relaxed and attend lectures without a knot in my stomach (which is not the case with other subjects). (P10)

However, some negative comments were also received. The main objection was that the discussion was dominated by "a handful of people [who] were constantly talking" (P20). This participant elaborates:

I think the more soft-spoken people didn't get to participate as much because they couldn't get a word in - which is good, in a way, because it means our discussions were dynamic and that is hard to achieve on Zoom. I just know I personally struggled with a way to enter a discussion without feeling like I would be interrupting someone. (P19)

One participant suggested that class discussion could have been better managed:

I feel like we could have covered some areas more or in depth if the professor [had] moderated the discussion more actively. (P4) 
Pavlović, Nataša (2021). 'It felt like we were all hanging out while talking about translation theory': Lessons learned from a flipped translation theory course in emergency remote teaching during the COVID-19 pandemic. Current Trends in Translation Teaching and Learning E, 8, 31 - 85. https://doi.org/10.51287/cttle20213

On the other hand, some participants appreciated the fact that they were not called out to participate:

What I loved most about [Zoom discussions] was that the professor did not call us out by name to answer questions [...] (this was actually my favorite Zoom class because of that very reason, I felt very anxious and on edge in the rest of the Zoom lectures in other subjects, and that influenced my online classes experience the most, in a negative way). (P10)

\subsubsection{Perception of teacher support}

Participants' perception of teacher support was coded along the three dimensions from the literature: structure, autonomy and involvement, as defined in section 2.2.

\subsubsection{Structure}

Structure support was referred to in 19 places in the participants' responses. The following codes were interpreted as contributing to structure support: organization, instrumental help, adjustment of teaching strategies and routine. Student comments highlighting structure support are given below. 
Pavlović, Nataša (2021). 'It felt like we were all hanging out while talking about translation theory': Lessons learned from a flipped translation theory course in emergency remote teaching during the COVID-19 pandemic. Current Trends in Translation Teaching and Learning E, 8, 31 - 85 . https://doi.org/10.51287/cttle20213

\section{a) Organization:}

This was by far the most organised online class. (P13)

In my opinion, all the elements of the course are very nicely planned and executed. (P22)

I enjoy when the syllabus of a course is systematically organized (each video had a proper introduction, examples, interesting topics, references and comparison with other topics we covered, conclusion) (P14)

b) Instrumental help:

You answer quickly if any of us have questions and you clarify everything. (P28)

[Y]ou gave us some guidelines, questions which helped make our answers more structured and also made us aware of what we should focus on. (P30)

c) Adjustment of teaching strategies:

[T] he lessons were organized and structured in a clear way, the explanations were slow enough and clear enough for us to comprehend new materials - maybe even more than actual lessons usually are. (P3) 
Pavlović, Nataša (2021). 'It felt like we were all hanging out while talking about translation theory': Lessons learned from a flipped translation theory course in emergency remote teaching during the COVID-19 pandemic. Current Trends in Translation Teaching and Learning E, 8, 31 - 85. https://doi.org/10.51287/cttle20213

Assignments were at times demanding, but they were always well structured to fit the purpose of a certain topic. (P29)

It's nice to see that teachers invest various types of effort in their classes and adapt to new realities, modernizing their teaching. (P26)

d) Routine:

Thank you for creating a routine and sticking to it, it has helped me to also create a routine and keep moving and get things done. (P30)

Students might have particularly appreciated routine in the context in which this course was delivered, six to nine months into the pandemic. As the same participant explained:

[A]s the semester went on, I found it harder to stay focused and it seems to me that I often drifted away and wasn't paying so much attention. I'm sure that this wouldn't have happened if we had been in the classroom. (P30)

As was mentioned above in 4.2.2.4., structure support was once also mentioned in a negative light, as the perceived lack of the teacher's management of the Zoom discussions. 
Pavlović, Nataša (2021). 'It felt like we were all hanging out while talking about translation theory': Lessons learned from a flipped translation theory course in emergency remote teaching during the COVID-19 pandemic. Current Trends in Translation Teaching and Learning E, 8, 31 - 85. https://doi.org/10.51287/cttle20213

\subsubsection{Autonomy}

Various aspects of autonomy support were mentioned by the participants, with 32 places in which the responses implicitly referred to autonomy. Autonomy support was seen in references to students being helped to develop critical thinking and formulate their own opinions on the topics, as well as being provided with choice as to when and how to learn. Respect for and acknowledgement of students' opinions is also a part of this dimension of support, as is the sense of relevance about the activities being done. Some examples of the participants' perception of autonomy support provided by the teacher are listed below.

a) Critical thinking:

What I really liked the most was that the course wasn't just you telling us what to do and what facts to learn, but rather sharing your knowledge and experience with us and then having discussions with everyone, to see all the different possibilities and approaches. (P21)

I find [this type of delivery] to be infinitely more useful because it reminds the student that they are part of a scientific community and invites them to approach the 
Pavlović, Nataša (2021). 'It felt like we were all hanging out while talking about translation theory': Lessons learned from a flipped translation theory course in emergency remote teaching during the COVID-19 pandemic. Current Trends in Translation Teaching and Learning E, 8, 31 - 85. https://doi.org/10.51287/cttle20213

theory in a critical way, which is exactly what this course does. (P12)

[W]hat I'm most content with is the amount of discussions about particular translation phenomena we had, which helped me learn how to express my own opinion with proper arguments and examples. (P14)

This course has also made me move away from my comfort zone. (P25)

\section{b) Respect:}

[Y]ou made Zoom a very welcoming space and gave everyone a chance to speak. I felt heard and like my opinions and thoughts mattered [...] (P19)

The abundance of opportunities to express my opinion has at times made me feel like my thoughts, too (and not translation only), matter! (P29)

c) Relevance:

Practical assignments encourage problem solving and critical thinking and they can help us with recognizing the learned material in real-life situations. (P4)

The assignments usually nicely complemented the videos and helped me see how the knowledge provided worked 
Pavlović, Nataša (2021). 'It felt like we were all hanging out while talking about translation theory': Lessons learned from a flipped translation theory course in emergency remote teaching during the COVID-19 pandemic. Current Trends in Translation Teaching and Learning E, 8, 31 - 85. https://doi.org/10.51287/cttle20213

in practice. [...] you guided us through discussions firmly and gave us a space to express ourselves and talk about topics that (should) concern us (at least regarding our future career). (P19)

\section{d) Choice}

[T] he professor did not call us out by name to answer questions, we could participate in the discussions freely, how, when, and if we wanted [...]. (P10)

Everything was available to me at all times and I could make notes based on our discussions or videos whenever I had the time and energy to do so. I believe this has helped me a lot with my studies in general, not only this course. (P11)

[T]hank you for making things as easy for us as the circumstances made possible (especially the fact that we had the option of watching the video lecture at any time from the weekend until Thursday) (P17)

\subsubsection{Involvement}

Like autonomy, involvement was also referred to in 32 places. Affection, attunement and dedication of resources were the aspects of involvement especially mentioned: 
Pavlović, Nataša (2021). 'It felt like we were all hanging out while talking about translation theory': Lessons learned from a flipped translation theory course in emergency remote teaching during the COVID-19 pandemic. Current Trends in Translation Teaching and Learning E, 8, 31 - 85 . https://doi.org/10.51287/cttle20213

\section{a) Affection:}

I would like to say a big thank you to prof. [...] because she really cares about her students and that they succeed later in life. (P6)

[T] he professor actively tries to create a comfortable environment for all students. (P4)

\section{b) Attunement:}

The professor was always understanding and helped us get through the hour and a half of the class, even on days when we were all visibly tired and exhausted. (P10)

\section{c) Dedication of resources:}

Thank you for putting in so much effort and time into making this course feel as normal as possible. (P13)

Thank you for putting in so much work into this course. It was a difficult term for all of us, but you have made it better. (P25)

You not only went out of your way to create a YouTube channel, but you also edited those videos so that they contained voiced-over tutorials and PowerPoint presentations, you didn't just simply record yourself giving the lessons [...]. (P30) 
Pavlović, Nataša (2021). 'It felt like we were all hanging out while talking about translation theory': Lessons learned from a flipped translation theory course in emergency remote teaching during the COVID-19 pandemic. Current Trends in Translation Teaching and Learning E, 8, 31 - 85. https://doi.org/10.51287/cttle20213

All of us really do appreciate your effort. [...] I've talked with other colleagues and we are all aware just how much effort you put into this course [...] (P28)

The professor went above and beyond to ensure the quality of education would not be hindered by the circumstances of the pandemic. (P12)

\subsection{Lessons learned}

Several lessons can be drawn from this, which can be applied primarily in the context of emergency remote teaching but also in future face-to-face formats. The most general lesson is that the flipped classroom model can be very suitable for courses such as translation theory, in spite of the challenges presented by online delivery in a course that was not designed for that format. However, for it to work well, some conditions have to be fulfilled. The first one is the inclusion of assignments that make the application and relevance of the theoretical issues apparent. This can be done via experimental translation assignments that engage the students, occasionally bringing them out of their comfort zone. Such assignments can have the added benefit of fostering student-student interaction, which is very valuable in the ERT context. The assignments should be clearly structured and related to the topic 
Pavlović, Nataša (2021). 'It felt like we were all hanging out while talking about translation theory': Lessons learned from a flipped translation theory course in emergency remote teaching during the COVID-19 pandemic. Current Trends in Translation Teaching and Learning E, 8, 31 - 85. https://doi.org/10.51287/cttle20213

of the week in a meaningful way for students to see the point of them.

Discussion forum assignments deserve more consideration. If the groups are big, as was the case in the present study (38 students), it might be a good idea to divide the students into smaller groups and have each group discuss a different aspect of the topic, then report to each other. Further, using the affordances of a social network, such as groups on Facebook, instead of in-built forum options in Moodle-type platforms can be considered in order to make the discussions less "rigid".

With respect to videos, a valuable lesson is that they need not be perfect in the technical sense (which is again particularly important in the context of ERT). If the videos resonate with students, minor technical flaws are likely to be disregarded. Participants in this study liked that the videos were clear and well structured, not too long, and featured the right amount of text. They also appreciated "a certain wackiness" (Bergmann \& Sams, 2012, p. 46) that the videos displayed, although of course not all teachers will wish to fool around in this way (I did it for my own enjoyment as well as the students'). As Bergmann and Sams (2012) stress, the advantage 
Pavlović, Nataša (2021). 'It felt like we were all hanging out while talking about translation theory': Lessons learned from a flipped translation theory course in emergency remote teaching during the COVID-19 pandemic. Current Trends in Translation Teaching and Learning E, 8, 31 - 85. https://doi.org/10.51287/cttle20213

of the flipped classroom model is that it is not a onesize fits all and that it can be very well adjusted to each teacher's personality and preferences. The videos require additional work up front but once recorded they can be reused and save time later. Also, videos already shared on YouTube by other people can be used instead of recording one's own. And finally, instead of the videos, other types of material can be used, such as reading assignments.

Like in-class discussions in face-to-face flipped classrooms, synchronous Zoom discussions are the crucial part of flipped courses. This is where rapport is established with students, by creating a welcoming atmosphere where everyone's opinions are valued. That is not without its challenges, as we have seen in this study, the major one being how to give everyone equal opportunity to speak without calling some students out by name and hushing others. A greater degree of teacher control over the discussion seems to be appreciated when a smaller group of students is seen to dominate the discussions.

All of the above lessons can be applied when we return to physical classrooms. The asynchronous activities mentioned in this paper (videos and 
Pavlović, Nataša (2021). 'It felt like we were all hanging out while talking about translation theory': Lessons learned from a flipped translation theory course in emergency remote teaching during the COVID-19 pandemic. Current Trends in Translation Teaching and Learning E, 8, 31 - 85. https://doi.org/10.51287/cttle20213

assignments) can be done by students at home, while the synchronous discussions take place in a physical classroom. The following opinion is illustrative of what participants in this study suggested when asked which aspects or elements of the present course, if any, could be used in future face-to-face delivery (Q10):

I believe everything [in this course] should be as it is. The discussions would be much easier face-to-face, but I believe that is the only thing that should be different. (P11)

Finally, student feedback highlights the impact of teacher support experienced during this course on their perception of the course as a whole. Student comments suggest a link between their positive experience of teacher support and positive academic emotions expressed in connection with the course. Thus, another lesson to be learned from this study might be a drive towards a "pedagogy of care" (Burke \& Larmar, p. 2020; cf. Noddings, 2012), not just in online environments and not just in times of global emergencies, when the need for this may be the most acute, but also after the educational disruption ends. 
Pavlović, Nataša (2021). 'It felt like we were all hanging out while talking about translation theory': Lessons learned from a flipped translation theory course in emergency remote teaching during the COVID-19 pandemic. Current Trends in Translation Teaching and Learning E, 8, 31 - 85. https://doi.org/10.51287/cttle20213

\section{CONCLUSION}

There are some obvious limitations of the present study. First of all, it examined only the participants' perceptions and not their knowledge or competence acquisition. Secondly, only a small group of students $(\mathrm{N}=30)$ participated in the study. The qualitative, action-research approach used here has its advantages, the main one being the richness and immediacy of the participants' responses. On the other hand, the evidence gathered in this study is not as robust as it would have been if a well-tested psychometric instrument had been used on larger numbers of participants. I nevertheless hope that the findings will be relevant to other translation (theory) teachers, who might be inspired to apply the flipped classroom model to their teaching of translation theory at a time when theoretical courses seem to be experiencing a crisis.

It is perhaps fitting to finish on a more personal note, as I started. When I planned and executed this course, I knew I wanted to support my students during a difficult time but I did not think of that support in terms of structure, autonomy or involvement. Like colleagues around the world, I was just trying to keep my head above the water and 
Pavlović, Nataša (2021). 'It felt like we were all hanging out while talking about translation theory': Lessons learned from a flipped translation theory course in emergency remote teaching during the COVID-19 pandemic. Current Trends in Translation Teaching and Learning E, 8, 31 - 85 . https://doi.org/10.51287/cttle20213

do the best I could under the circumstances. That the course proved to be such a success was a surprise to me as much as it must have been to the students. It is only with the benefit of hindsight that I can see that something good has come out of the pandemic. It made me think outside the box. Although constant attempts at innovation have been the hallmark of my teaching career, they have mostly focused on my practical translation courses. It is perhaps telling that it took a global emergency to change the way I taught translation theory. On a broader scale, it might not be overly optimistic to hope that the pandemic might reframe the role of theory and its place in higher education, perhaps reinventing humanities in the post-COVID-19 era in the process.

\section{REFERENCES}

Agost, R., \& Ordóñez-López, P. (2015). Translation theory. Myths, prejudices and realities. Babel, 61(3), 361-380.

https://doi.org/10.1075/babel.61.3.03ago 
Pavlović, Nataša (2021). 'It felt like we were all hanging out while talking about translation theory': Lessons learned from a flipped translation theory course in emergency remote teaching during the COVID-19 pandemic. Current Trends in Translation Teaching and Learning E, 8, 31 - 85. https://doi.org/10.51287/cttle20213

Agost, R., \& Ordóñez-López, P. (2018). Hermēneus. Revista de traducción e interpretación, 20, 57-85. https://doi.org/10.24197/her.20.2018.57-85

Bergmann, J., \& Sams, A. (2012). Flip your classroom. Reach every student in every class every day. ISTE \& ASCD.

Bozkurt, A., \& Sharma, R. C. (2020). Emergency remote teaching in a time of global crisis due to coronavirus pandemic. Asian Journal of Distance Education, 15(1), i-vi.

Burke, K., \& Larmar, S. (2020). Acknowledging another face in the virtual crowd: Reimagining the online experience in higher education through an online pedagogy of care. Journal of Further and Higher Education. https://doi.org/10.1080/0309877X.2020.18045 $\underline{36}$.

Centre for Teaching, Learning and Technology. (n.d). Flipped Classroom. University of British Columbia. http://flexiblelearning2015.sites.olt.ubc.ca/files/2015/03/flip ped-classroom.pdf 
Pavlović, Nataša (2021). 'It felt like we were all hanging out while talking about translation theory': Lessons learned from a flipped translation theory course in emergency remote teaching during the COVID-19 pandemic. Current Trends in Translation Teaching and Learning E, 8, 31 - 85 . https://doi.org/10.51287/cttle20213

Deci, E. L., \& Ryan, R. M. (2000). The "what" and "why" of goal pursuits: Human needs and the self-determination of behavior. Psychological Inquiry, 11, 227-268.

https://doi.org/10.1207/S15327965PLI1104_0 1

Deng, L. (2018). The project-based flipped learning model in business English translation course: Learning, teaching and assessment. English Language Teaching, 11(9), 118-128. https://doi.org/10.5539/elt.v11n9p118

Di Mango, D. (2019). Does teaching theory enhance students' translation competence? Viewpoints, expectations, findings. inTRAlinea Special Issue: New Insights into Translator Training. http://www.intralinea.org/specials/article/2425

Gerber, L., Orlando, M., \& Tobias, S. (2020). 'Blended learning' in the training of professional translators. Translatologia, $1 / 2020$.

http://www.translatologia.ukf.sk/2020/02/blen ded-learning-in-the-training-of-professionaltranslators/ 
Pavlović, Nataša (2021). 'It felt like we were all hanging out while talking about translation theory': Lessons learned from a flipped translation theory course in emergency remote teaching during the COVID-19 pandemic. Current Trends in Translation Teaching and Learning E, 8, 31 - 85. https://doi.org/10.51287/cttle20213

Lei, H., Cui, Y., \& Chiu, M. M. (2018). The relationship between teacher support and students' academic emotions: A meta-analysis. Frontiers in Psychology, 8(2288), 1-12. https://doi.org/10.3389/fpsyg.2017.02288

Nietzel, M. T. (2019, January 7). Whither the humanities: The ten-year trend in college majors. Forbes.

https://www.forbes.com/sites/michaeltnietzel/20 19/01/07/whither-the-humanities-the-ten-yeartrend-in-college-majors/?sh=15626cb764ad

Noddings, N. (2012). The caring relation in teaching. Oxford Review of Education, 38(6), 771-781. https://doi.org/10.1080/03054985.2012.745047

Sams, A., \& Bergmann, J. (2013). Flip your students' learning. Educational Leadership, 70(6): 16-20.

Shu, X. (2015). An empirical study on a flipped classroom in open university teaching based on an ecological perspective: A case study on a translation theory and practice course". AAOU Journal, 10(1), 53-63. 
Pavlović, Nataša (2021). 'It felt like we were all hanging out while talking about translation theory': Lessons learned from a flipped translation theory course in emergency remote teaching during the COVID-19 pandemic. Current Trends in Translation Teaching and Learning E, 8, 31 - 85 . https://doi.org/10.51287/cttle20213

Shuttleworth, M. (2001). The role of theory in translator training: Some observations about syllabus design. Meta: journal des traducteurs / Meta: Translators' Journal, 46(3), 497-506. https://doi.org/10.7202/004139ar

Skinner, E. A., \& Belmont, M. J. (1993). Motivation in the classroom: Reciprocal effects of teacher behavior and student engagement across the school year. Journal of Educational Psychology, 85(4), 571-581. https://doi.org/10.1037/0022-0663.85.4.571

Skinner, E. A., Furrer, C., Marchand, G., \& Kindermann, T. (2008). Engagement and disaffection in the classroom: Part of a larger motivational dynamic? Journal of Educational Psychology, 100(4), 765-781. https://doi.org/10.1037/a0012840

Stanojević, M. M., \& Pavlović, N. (in press). 'Juggling while running': emergency remote teaching of translation in times of educational disruption. 
Pavlović, Nataša (2021). 'It felt like we were all hanging out while talking about translation theory': Lessons learned from a flipped translation theory course in emergency remote teaching during the COVID-19 pandemic. Current Trends in Translation Teaching and Learning E, 8, 31 - 85. https://doi.org/10.51287/cttle20213

Tsai, Y., \& Tsai, A. (2017). Flipped translation training: The student perception. Studies in English Language and Literature, 39: 187-206. http://ctld.ntu.edu.tw/rp/report/103_08.pdf

Vansteenkiste, M. (n.d). Basic psychological needs. Autonomy, competence, and relatedness. Center for Self-Determination Theory. https://selfdeterminationtheory.org/applicationbasic-psychological-needs/

Vottonen, E., \& Kujamäki, M. (2021). On what grounds? Justifications of student translators for their translation solutions. The Interpreter and Translator Trainer, 15(3), 306-325. https://doi.org/10.1080/1750399X.2021.18915 $\underline{14}$

\section{APPENDICES}

\section{Appendix 1 - Sample videos}

Sample videos from the beginning, middle and end of the course can be found on the following links respectively:

Types of translation: https://youtu.be/h05CvHt-CIg 
Pavlović, Nataša (2021). 'It felt like we were all hanging out while talking about translation theory': Lessons learned from a flipped translation theory course in emergency remote teaching during the COVID-19 pandemic. Current Trends in Translation Teaching and Learning E, 8, 31 - 85. https://doi.org/10.51287/cttle20213

Skopos theory: https://youtu.be/Q01Z9vyCIGg

Translation ethics: https://youtu.be/Aeykht4S7_A

Links to other videos can be obtained on request.

\section{Appendix 2 - The questionnaire}

1. Please rate each element of the course on a scale of $1-5$

( 1 = not at all useful; 5 = very useful).

Choose ZERO if you did not watch/do/attend).

\begin{tabular}{|l|l|l|l|l|l|l|}
\hline & 1 & 2 & 3 & 4 & 5 & 0 \\
\hline Videos & & & & & & \\
\hline Translation assignments & & & & & & \\
\hline Forum assignments & & & & & & \\
\hline Zoom discussions & & & & & & \\
\hline
\end{tabular}

2. Please explain or comment on your response.

3. In terms of the WAY it was delivered (i.e. not the topic itself), how does this course compare to other THEORETICAL courses you've had during your years at the university? 
Pavlović, Nataša (2021). 'It felt like we were all hanging out while talking about translation theory': Lessons learned from a flipped translation theory course in emergency remote teaching during the COVID-19 pandemic. Current Trends in Translation Teaching and Learning E, 8, 31 - 85. https://doi.org/10.51287/cttle20213

- The delivery of most other theoretical courses was much better than this one.

- The delivery of most other theoretical courses was better than this one.

- The delivery of this course was neither better nor worse than most other theoretical courses.

- This delivery of this course was better than the delivery of most other theoretical courses.

- This delivery of this course was much better than the delivery of most other theoretical courses.

4. You can explain or comment on your response.

5. Please rate your level of agreement with this statement: "Even if this course was not obligatory for translation students, I would still recommend it to colleagues who wish to become translators."

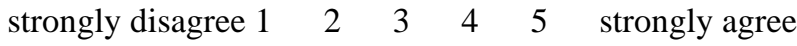

6. How would you rate your engagement in the Zoom discussions?

- I took an active part in the discussions a lot of the time.

- I listened actively, and sometimes spoke.

- It was mostly passive; I listened but did not speak much. 
Pavlović, Nataša (2021). 'It felt like we were all hanging out while talking about translation theory': Lessons learned from a flipped translation theory course in emergency remote teaching during the COVID-19 pandemic. Current Trends in Translation Teaching and Learning E, 8, 31 - 85. https://doi.org/10.51287/cttle20213

- I listened, but only with "one ear".

- I connected to the meeting because I felt I should, but I did not really listen to discussions.

- Other...

7. Please assess how much you think you have learned about translation in this course.

$\begin{array}{lllllll}\text { almost nothing new or useful } & 1 & 2 & 3 & 4 & 5 & \text { a lot }\end{array}$ of new and useful stuff

8. What did you particularly like about this course? (If nothing, pls write "nothing".)

9. What improvements, if any, would you suggest if this course had to be delivered ONLINE again? (If none, pls write "none".)

10. What aspects or elements of the present course, if any, do you think could be used in future FACE-TO-FACE delivery of this course. (If none, pls write "none".) 
Pavlović, Nataša (2021). 'It felt like we were all hanging out while talking about translation theory': Lessons learned from a flipped translation theory course in emergency remote teaching during the COVID-19 pandemic. Current Trends in Translation Teaching and Learning E, 8, 31 - 85. https://doi.org/10.51287/cttle20213

11. In what ways has the course been useful/helpful for you personally? (If it hasn't been useful/helpful, please explain why not.)

12. Use this space if you would like to add anything about this topic (optional). 